\title{
A CONSTRUÇÃO DAS IDENTIDADES SEXUAIS NAS PRÁTICAS DISCURSIVAS: O DISCURSO ESCRITO NOS TEXTOS ESCOLARES
}

\author{
BÁRBARA ANGÉLICA APARECIDA CARVALHO ${ }^{1}$ \\ ELISABETE FERREIRA ESTEVES CAMPOS
}

\section{RESUMO}

Este trabalho problematiza o discurso de masculinidade hegemônica veiculado nos livros didáticos e, por consequência, no contexto escolar, através dos textos e gêneros discursivos que os compõem. Nesta pesquisa, realizamos um levantamento bibliográfico e selecionamos quatro estudos acadêmicos que analisam questões de gênero e sexualidade nos livros usados em aulas. Concluímos que essas obras didáticas analisadas pelos pesquisadores apresentam textos cujas cargas ideológicas manisfestam o poder simbólico do discurso dominante de construção das masculinidades, sobretudo da masculinidade hegemônica. Tal discurso assegura as relações de poder que pautam a construção de outras identidades, provocando sanções, através da violência de gênero, ao que dele difere, podendo resultar em exclusão e violação dos direitos de acesso e permanência na escola.

Palavras-chave: Identidades sexuais; Práticas discursivas; Textos escolares.

\section{ABSTRACT}

This work problematizes the discourse of hegemonic masculinity published in textbooks and, consequently, in the school context, through the texts and discursive genres that compose them. In this research, we did a bibliographical research of four academic

1 «La construction des identités de genre dans les pratiques discursives: le discours écrit dans les manuels pédagogiques». Mestranda em Ciências da Linguagem e da Comunicação, Université de Neuchâtel, Suíça. Prof. orientadora: Simona Pekarek Doehler. 
studies that look at gender and sexuality issues. We conclude that the textbooks are based on texts which ideological tenor manifests the symbolic power of the dominant discourse of construction of masculinities, especially of hegemonic masculinity. This discourse ensures the power relations that guide the construction of other identities, causing sanctions, through gender violence, to everything that differs from it, resulting in rejection and violation of the rights of access and permanence in school.

Keywords: Sexual identities; Discursive practices; School texts.

\section{INTRODUÇÃO}

A construção das identidades sociais, especificamente as identidades sexuais, ocorre nas práticas discursivas em contextos históricos e sociais, nas quais os interlocutores se constituem mutuamente, pois as práticas discursivas são também práticas de construção de identidade social.

Os conceitos de gênero e identidades de gênero são construções socioculturais veiculadas através dos discursos disponíveis nas diversas esferas de atividade humana, presentes nas múltiplas instituições sociais, portanto, também na escola, que passa a reproduzir os significados construídos pelos discursos dominantes, segundo os estudos de Moita Lopes (2002).

Neste artigo, problematizamos os discursos presentes nos livros didáticos escolares, questionando a possível contribuição ao projeto de masculinidade hegemônica. Para investigar tal problemática, realizamos uma pesquisa bibliográfica (SALVADOR, 1986), em um movimento de interlocução crítica com o material analisado (LIMA; MINOTO, 2007). Após levantamento de pesquisas sobre o tema, selecionamos quatro estudos acadêmicos que analisam questões de gênero e sexualidade nos livros didáticos usados nas instituições escolares. Nosso objetivo central foi investigar em que medida esses estudos identificam a posição de poder do discurso relativo à masculinidade como projeto hegemônico. Fundamentamos nossas análises em alguns referenciais teóricos, especialmente a obra de Moita Lopes (2002), Grossi (2012), Foucault (1997, 1989, 1999), Bakhtin (2003) e Bourdieu (1989, 2010). 
Consideramos que os discursos e seus significados são construtores da realidade e das identidades dos sujeitos envolvidos nas ações comunicativas. Assim, os gêneros dos discursos que circulam nos contextos escolares podem assegurar o projeto de dominação masculina e sancionar negativamente todo contra discurso através da violência de gênero.

Essa perspectiva sociointerecionista de discurso como construtor de identidades sociais mobilizou a análise, nesta investigação, sobre como a construção de significados dos gêneros do discurso constituintes dos livros didáticos podem implicar na construção das identidades, sobretudo a identidade de gênero, visto que os gêneros discursivos estudados durante o processo de escolarização veiculam valores e ideologias presentes nos discursos aos quais estão atrelados.

Concluímos este trabalho demonstrando que as quatro pesquisas analisadas evidenciam a tendência de manutenção do discurso de masculinidade hegemônica. Em nosso entendimento, as possíveis consequências no ambiente escolar podem ocorrer em diferentes perspectivas, especialmente com a exclusão, expulsão e violação de direitos de acesso e permanência na escola de estudantes que não se identificam com tal discurso. Anunciamos, como possibilidade, a ampliação dos debates que promovam um olhar crítico para os materiais e livros didáticos, problematizando os significados construídos pelas classes dominantes, tendo em vista a formação cidadã dos educandos.

\section{A CONSTRUÇÃO DA MASCULINIDADE HEGEMÔNICA}

A masculinidade hegemônica é uma construção histórico-social por meio da qual os homens aprendem a desempenhar a masculinidade, configurando as práticas de gênero que historicamente asseguraram sua posição de dominação.

Em suas análises sobre as masculinidades, Moita Lopes (2002), aponta que é necessário abordá-las sempre em relação à feminilidade e à sexualidade, pois gênero e sexualidade são construídos relacionalmente. Assim, a masculinidade é simultaneamente um lugar de relações de gênero, práticas nas quais 
homens e mulheres tomam um lugar nos gêneros, e os resultados dessas práticas nas experiências corpóreas, cultura e personalidade dos indivíduos. Segundo o projeto de masculinidade hegemônica, há uma função controladora das relações de gênero que requer vigilância total da parte masculina, visando separá-la das mulheres e de práticas homoeróticas.

O menino ao nascer é socializado na infância, na maior parte das sociedades, pela mãe, construindo um forte vínculo que deve, segundo o modelo hegemônico, ser rompido ao longo de sua socialização, pois esse mesmo menino é obrigado a provar que não é um bebê, uma garota ou um "gay", sujeitos que podem possuir fortes vínculos com a figura materna sem comprometimento com o projeto de masculinidade.

Ainda no dizer de Moita Lopes (2002, p.155), "a 'masculinidade' é imposta pela vida em família e pelos primeiros amigos, e a escola continua com essa imposição como a literatura sobre gênero e sexualidade nas escolas mostra", e segue afirmando que a sexualidade é a heterossexualidade ou heterossexualidade compulsória que, na adolescência, torna-se prática coletiva e imposta pelos pares como natural.

O autor apresenta outros traços característicos da masculinidade hegemônica, como a agressividade, atitudes homofóbicas, desejo sexual natural, esportes e racionalidade (MOITA LOPES, 2002, p. 157-158). Afirma, ainda, que a execração de práticas homoeróticas faz parte do pertencimento a grupo. Para isso, as instituições, incluindo as escolas, perpetuam atitudes homofóbicas pela necessidade que os garotos machos sentem de expulsar de dentro de si mesmos e do grupo todos os outros garotos que não exerçam práticas consideradas tipicamente masculinas, segundo os padrões vigentes. Portanto, os meninos aprendem a usar o gênero para controlar a sexualidade.

Quando se refere à racionalidade, a ideologia patriarcal, como afirma Moita Lopes (2002, p.158), assume os homens como mais racionais que as mulheres, sendo, portanto, para o projeto de masculinidade hegemônica, os sujeitos adaptados a ocupar os cargos executivos ou os campos de conhecimento tecnológico. 
Grossi (2012, p.7), por sua vez, apresenta a agressividade como um dos traços construtores da masculinidade hegemônica, naturalizada como característica inata ao sexo. Assim, não só é tolerado que os meninos apresentem comportamentos agressivos, como os ritos de passagem na construção da masculinidade também são marcados por violência, seja ela simbólica ou corporal.

Os homens procuram adaptar seu comportamento, constantemente, ao modelo tradicional para assegurar o reconhecimento da masculinidade e essa naturalização, que define identidades sexuais a partir das masculinidades, é dada por meio do poder simbólico. Segundo Pierre Bourdieu (1998, p.8), "o poder simbólico é, com efeito, esse poder invisível o qual só pode ser exercido com a cumplicidade daqueles que não querem saber que lhe estão sujeitos ou mesmo que o exercem".

Nesse sentido, para Bourdieu, o poder circula na sociedade através dos sistemas simbólicos, como a língua, a arte e a religião, por exemplo, cuja reprodução e validação de paradigmas, ideias e ordem social se dá através dos símbolos que são instrumentos de integração social. Conforme Bourdieu (1989):

É assim que os sistemas simbólicos cumprem a sua função política de instrumentos de imposição ou de legitimação da dominação, que contribuem para assegurar a dominação de uma classe sobre a outra (violência simbólica) dando o reforço da sua própria força às relações de força que as fundamentam e contribuindo assim, segundo a expressão de Weber, para a domesticação dos dominados (p. 10).

No campo da construção das identidades de gênero e sexualidades, a sanção aos discursos contrários ao dominante se manifesta através da violência de gênero, definida por Sardenberg (2011):

Por "violência de gênero", refiro-me a toda e qualquer forma de agressão ou constrangimento físico, moral, psicológico, emocional, institucional, cultural ou patrimonial, que tenha por base a organização social dos sexos e que 
seja impetrada contra determinados indivíduos, explícita ou implicitamente, devido à sua condição de sexo ou orientação sexual (p. 01).

Em reação ao discurso dominante, são construídos os contra discursos dos grupos marginalizados, como o de igualdade de gênero, da criminalização da homofobia e todas as reivindicações dos grupos feministas e de LGBTs (lésbicas, gays, bissexuais, travestis e transexuais). Tais debates, no entanto, não constituem o currículo escolar, que, ao aderir ao projeto social hegemônico, fortalece tal ideologia, podendo contribuir para a exclusão e expulsão dos que não se identificam com o projeto de masculinidade predominante no discurso escolar.

Como agravante, temos o fato de que as políticas públicas não têm avançado no enfrentamento dessa questão. O tema relativo à desigualdade de gênero e discriminação gerou grande polêmica no Plano Nacional de Educação (PNE), culminando com a retirada do termo "gênero". A polêmica se estendeu para os planos dos estados e municípios, muitos deles contrários ao debate. Na terceira versão da Base Nacional Comum Curricular, o tema também foi excluído, seguindo a lógica do PNE, gerando manifestos de diversos grupos.

\section{O DISCURSO E A CONSTRUÇÃO DA IDENTIDADE SOCIAL: LEGITIMAÇÃO E PODER}

O traço mais característico do discurso é a sua natureza social. Os significados são construídos no processo de interlocução atribuindo uma dimensão social aos gêneros mobilizados na interação entre os sujeitos.

As pessoas utilizam a linguagem em relação a alguém que, da mesma forma, a utiliza em relação a elas, evidenciando a natureza dialógica do discurso, assim, constrói-se o mundo e as pessoas nas circunstâncias sócio-histórico-culturais nas quais estão situadas. Pode-se, diante de tal fato, compreender o discurso como forma de ação social, na qual as pessoas agem sobre o mundo e umas sobre as outras, construindo a realidade social e a si mesmas. 
Para Moita Lopes (2002, p. 34) “a construção da identidade social é vista como estando sempre em processo, pois é dependente da realização discursiva em instâncias particulares: os significados que os participantes dão a si mesmos e aos outros engajados no discurso". Tal afirmação implica o fato de que a identidade está sempre em construção, nunca concluída, pois o indivíduo, ao antecipar como seu interlocutor pode responder na interação, compõe-se de diferentes formas.

A linguagem, entendida como discurso, é mecanismo de poder simbólico construtor da realidade, cuja força das palavras é exercida na ação comunicativa, construindo significados, veiculando valores, ideologias e lutas ideológicas presentes no cotidiano de agentes sociais, configurando, desse modo, formas de dominação e exercício de poder.

Os significados do discurso não são construídos apenas localmente, no momento de interação, mas, devido a sua natureza sócio-histórica, são também institucionais e culturais. Por consequência, as práticas discursivas revelam crenças, valores, posições políticas dos interlocutores e possibilitam que esses significados, construídos localmente, se relacionem de forma mais ampla a contingências políticas, culturais, históricas e institucionais em que situam essas mesmas práticas discursivas.

A linguagem comunica a posição que o sujeito ocupa, constituindo-se como arena em que se travam jogos ideológicos e onde se exercem formas de poder. Para Bordieu (1989, p.14), o poder não está nas palavras propriamente, mas na legitimidade conferida pelos falantes.

O poder simbólico é a manifestação transmutada de outros poderes em situações de dominação real, nas quais tais poderes se intercomunicam fazendo com que as relações sociais sejam, constantemente, atingidas por eles. A legitimação ocorrida na linguagem é um ato ideológico que assegura a dominação e permite estabelecer o que é aceitável a um falante ou grupo falar de um lugar a outro, posiciona e hierarquiza, incidindo sob todo o processo de institucionalização de valores na sociedade.

No entanto, Foucault (1989) também pontua que o poder gera resistência, construindo, por sua vez, identidades em po- 
sição de resistência. Uma pessoa posicionada de determinado modo em um discurso específico pode resistir a essa posição e criar um contra discurso, recolocando-se em outra posição no processo discursivo.

Outra característica crucial do entendimento de identidade social como um processo constante de construção, é o fato de que um mesmo sujeito possui identidades múltiplas na sociedade, pois está inscrito em práticas discursivas diversas por meio de identidades sociais diferentes e contraditórias. Segundo Moita Lopes (2002, p. 36), “o poder atravessa a sociedade em diferentes direções, dependendo das relações sociais nas quais as pessoas se envolvem por meio de diferentes práticas discursivas".

Os sujeitos não escolhem por vontade suas múltiplas identidades, essa escolha é determinada pelas práticas discursivas, imbuídas de poder, mesmo que possam apresentar resistência a tais práticas, ou seja, as identidades não são fixas, emergem na interação com outros indivíduos agindo em práticas discursivas específicas nas quais estão posicionados.

Segundo Moita Lopes (2002), a natureza dialógica do discurso é marcada pela alteridade, pois sempre se utiliza a linguagem em relação a alguém, num processo de coprodução, no qual as identidades não são inerentes aos sujeitos, mas construídas no processo de construção de significado e a multivocalidade, que evidencia a pluralidade de discursos coexistentes em qualquer discurso e, através da qual, é possível perceber que, na construção das identidades, os fatores biológicos não são definitivos e sim, como esses e outros fatores, são representados nas práticas discursivas situadas socialmente, historica e culturalmente.

Dessa forma, torna-se possível concluir que as identidades são complexas, inacabadas, reposicionadas nas práticas discursivas segundo o outro, a antecipação da resposta do outro na interação e a posição que esse outro ocupa nesse processo constante, local, social e histórico, além de instituicional, de cocriação de significados., Tal fato é resultado da compreensão da natureza dialógica do discurso e seu entendimento como forma de ação no mundo. 


\section{AS PRÁTICAS DISCURSIVAS NAS AULAS}

O discurso como forma de ação no mundo pressupõe que os sujeitos envolvidos nas práticas discursivas local e sócio-histórico-culturalmente situadas constroem os significados e a si mesmos, posicionados em relações de poder assimétricas. Os projetos de construção das masculinidades veiculam as ideologias do discurso dominante, legitimado, assim, como norma pela qual se definem as outras identidades sexuais, sendo que os sistemas simbólicos de poder que perpassam a sociedade são responsáveis por assegurar tal discurso e naturalizar a violência de gênero. Essa recai sobre os indivíduos que confrontam, com seus contra discursos, os valores construídos nos discursos de masculinidade dominante.

Uma das instituições sociais que reproduz tais símbolos de poder é a escola, sendo os discursos veiculados no ambiente escolar formadores de identidades. Para Moita Lopes (2002), uma parte importante das práticas discursivas realizadas em sala de aula envolve a aprendizagem de como posicionar-se no discurso segundo o outro. Portanto, em como compor as identidades a partir do que o outro representa para esse falante e vice-versa, tanto nos textos orais ou escritos usados em aula, como no mundo escolar: colegas, professores e todos os outros agentes escolares.

Segundo o autor, a escola possui um papel central na construção das identidades dos alunos, já que se configura como o primeiro espaço social fora de casa do qual o estudante participa passando um considerável período do dia. O professor é quem desempenha o papel de autoridade no processo de construção de significados que, por sua vez, possuem alto crédito social, por ser a escola uma instituição central de construção dos saberes em diversas sociedades.

Para Bakhtin (2003), a palavra está sempre carregada de um sentido ideológico, vivencial, portanto, não são simples palavras que os indivíduos ouvem ou pronunciam, e sim mentiras, verdades, coisas boas ou más, importantes ou triviais.

A construção de significados em sala de aula é uma prática conjunta e, nesse sentido, Freire (1987) propõe a dialogicidade 
como dimensão emancipadora. É por meio do diálogo dos alunos entre si e com os professores que se estabelecem relações comunicativas, em cujo projeto discursivo está a possibilidade da transformação do educando em sujeito da sua própria história.

A desconstrução da dicotomia educador versus educando, estrutura observada na educação bancária denunciada pelo autor, ocorre na perspectiva da educação problematizadora que promove a reflexão crítica, fundamentada teoricamente, visando às possibilidades de transformação.

Para Freire (1987), é só através desse ato eminentemente humano que é o processo de educação, que temas constituintes da realidade social podem ser problematizados tornando-se possível caminhar rumo à liberdade daqueles que são oprimidos pelos discursos dominantes, cuja violência simbólica reflete a ordem de dominação social que é também construída e legitimada no discurso. Compreender o discurso como construtor de identidades e reconhecer que os discursos dominantes oprimem tudo que difere de sua ideologia, torna-se fundamental para que a escola, enquanto instituição central de construção de saberes, possa enveredar para uma transformação no e do contexto social, através da desconstrução ou elaboração de contra discursos das minorias, ou estará reafirmando a dominação vigente no processo bancário de educar.

Cabe ao professor o papel de mediador nesse processo, considerando o pensamento e linguagem dos alunos, seus conhecimentos prévios, as identidades construídas no âmbito familiar, experiências, como também as características do gênero do discurso mobilizado e sua função em práticas sociais. Contudo, para que o docente assuma uma prática reflexiva no tratamento dos gêneros do discurso e sua direta relação com a construção de identidades sociais, é necessária uma formação também reflexiva, sem marcas de superficialidade e enquadres limitadores.

Assim, dado os conceitos apresentados ao longo deste texto, torna-se possível afirmar que as aulas de línguas ou de conteúdos específicos podem constituir-se como práticas emancipadoras, caso o trabalho com os gêneros discursivos não se limite às análises puramente linguísticas ou conteudistas, com apagamento de seu 
aspecto social e sua implicação na construção da realidade e das identidades sociais dos sujeitos que a constituem.

\section{O DISCURSO DOS LIVROS DIDÁTICOS NOS ANOS INICIAIS DE ESCOLARIZAÇÃO}

Tomando como base os referenciais teóricos abordados, analisamos quatro estudos relativos ao tema. $\mathrm{O}$ primeiro estudo analisado foi publicado por Xavier Filha (2014), intitulado "Gênero, corpo e sexualidade nos livros para a infância“, decorrente de pesquisas coordenadas pela autora, em que analisa os temas e linguagem adotadas e suas possibilidades de produzir subjetividades na infância, bem como por aquilo que produzem e veiculam. Segundo suas pesquisas "as questões relacionadas ao corpo sexuado de meninas e de meninos e à sua educação de gênero aparecem como temas fundamentais para a educação, sobretudo com a ênfase na heterossexualidade como norma única e desejável” (XAVIER FILHA, 2014, p. 166). A autora problematiza os textos que "pretendem produzir uma infância normal", com foco em aspectos "biológicos, médicos, psicológicos, sociais e, principalmente, morais", com um discurso do que se considera "a verdade, acima de tudo na educação de crianças".

Com relação aos livros para a infância, eles também instigam a reflexão da criança a partir daquilo que "se" considera correto para a sexualidade e para o gênero nesse período da vida. Observamos que pouquíssimos livros têm a participação efetiva das crianças em seus textos e ilustrações, ao contrário, possuem linguagens e preceitos adultos, fazendo com que a obra se mantenha sob a tutela dos discursos adultos (XAVIER FILHA, 2014, p. 166).

A pesquisa da autora nos leva a considerar que, desde a infância, procura-se introjetar nas crianças a ideia de "norma única e desejável". Desta forma, as narrativas voltadas para o público infantil, pautadas no projeto de masculinidade hegemônica, podem ser reforçadas no contato com os livros que são usados na infância. $\mathrm{Na}$ continuidade de sua pesquisa, a autora propôs 
que as próprias crianças participassem da produção dos livros "com a finalidade de discutir temáticas como corpo, gênero e violências contra crianças” (XAVIER FILHA, 2014, p. 167). Ao dar voz às crianças, no entendimento da autora, é possível criar outras possibilidades de produção de subjetividades.

Apesar de não ter sido objeto de análise da autora, consideramos importante destacar que, em tratando-se da educação escolar na infância, o foco no processo de alfabetização nos anos iniciais torna o diálogo fundamental e outras temáticas podem ser abordadas, promovendo o contato com a diversidade de gêneros discursivos e construção de outros significados.

A alfabetização como um processo amplo, não se restringe a codificar-decodificar letras e palavras. Como argumenta Ferreiro (1998) a compreensão da escrita como um sistema de representação da linguagem se opõe ao entendimento da língua escrita como código, isto porque o código corresponde a um único e inequívoco significado, enquanto um sistema alfabético implica na construção de diferentes significados, ou seja, as palavras não existem fora de seu contexto de significação. Portanto, para a autora, alfabetizar pressupõe a compreensão do discurso e seus significados.

Ao participar das práticas de alfabetização, os estudantes vão construindo, compreendendo e interpretando significados, em um processo de socialização e trocas simbólicas com os outros sujeitos. A relevância do papel da escola se torna evidente, uma vez que alfabetização é uma prática que envolve os aspectos culturais e sociais da realidade, para a compreensão das intenções comunicativas nos vários lugares e situações cotidianas.

Os gêneros do discurso, como objetos de inserção no mundo da leitura e aprendizado da língua, carregam a carga ideológica das práticas discursivas que constroem os seus significados. Em sala de aula, há uma nova construção de significados que pode ser ou não emancipadora do discurso dominante, cabendo ao professor dialogar com os alunos, numa atitude reflexiva, capaz de promover debates que assegurem a expressão de todas as matizes constituintes das identidades sociais, como sexualidade, identidade de gênero, etnia, classe social etc. 
Mediante tais reflexões é relevante dar voz às crianças, como propõe Xavier Filha (2014), para que possamos romper com a leitura hegemônica que pode ser preconceituosa e excludente.

Contudo, tais debates precisam ser considerados na formação dos professores, uma vez que ainda não fazem parte, de forma predominante, do universo escolar. Nesse processo formativo de professores, as políticas educacionais precisam ser objeto de estudo e reflexão, visto estarem privilegiando um discurso dominante que desconsidera a diversidade, pois os elementos constitutivos das identidades, sexualidade e gênero são apagados no discurso escolar, quando não ostensivamente contestados e excluídos de propostas que visam a introdução do tema, como pode ser observado no veto às 35 menções de estratégias relacionadas à identidade de gênero e orientação sexual apresentadas no Plano Nacional de Educação (PNE, 2014).

Nesse sentido, é relevante que professor amplie seus espaços formativos, participando de fóruns de debates, eventos e inserindo-se em projetos de pesquisas, considerando seu papel de agente social capaz de assegurar relações mais democráticas e construir, junto aos seus alunos, a emancipação das práticas discursivas opressoras.

\section{GÊNERO E SEXUALIDADE EM LIVROS DIDÁTICOS DE CONHECIMENTOS ESPECÍFICOS}

Para os propósitos de nossa investigação, analisamos também três estudos acadêmicos relativos aos livros didáticos usados em disciplinas de conhecimentos específicos: ciências, biologia e inglês.

$\mathrm{Na}$ análise dos livros didáticos de Ciências, realizada por Martins e Hoffman (2007) no trabalho intitulado "Os papéis de gênero nos livros didáticos de Ciências", constata-se que os discursos reafirmam a matriz bipolar "masculino" e "feminino" nas relações de gênero e, por consequência, os papéis de gênero associados a esses conceitos.

As autoras analisaram a representação do significado de ser homem e ser mulher em determinada sociedade, a partir dos valores simbólicos expressos em três categorias: comportamento de 
menina e de menino discutido pela vestimenta (cores, acessórios, estampas e corte de cabelo), brincadeiras e atividades cotidianas; papel do homem e da mulher no processo produtivo, discutido pela análise do tipo de trabalho e remuneração atribuídos aos dois gêneros e, por fim, exemplos de papéis de gênero conferidos aos homens e às mulheres inseridos num contexto sociocultural.

Os resultados apresentados pelas autoras evidenciam a questão conceitual dos autores do material didático em adotar sexo biológico por gênero, limitando, portanto, as identidades na dicotomia homem versus mulher (dois sexos, dois gêneros) e estabelecendo papéis sociais para os sujeitos categorizados nesses dois grupos. Apagam-se as identidades sexuais plurais e constrói-se um discurso, fomentando pelos valores simbólicos, do significado de ser homem e de ser mulher.

Nos resultados obtidos na discussão comportamento de menino e de menina, os dados reafirmam a simbologia da mulher como ser delicado e frágil, vestindo roupas rosas e de estampas florais, de cabelos longos e adereçados, contrapondo-se aos meninos sempre vestidos de shorts e camisetas confortáveis, majoritariamente na cor azul, calçando tênis e representados de cabelos curtos. No que se referem às brincadeiras, as meninas, frequentemente, executam brincadeiras associadas às tarefas domésticas e criação dos filhos (portam bonecas, fogões, ferros de passar), em ambiente seguro e próximo da casa e vigilância de seus tutores, enquanto os meninos executam brincadeiras simbolicamente livres, como soltar pipas, correr, jogar futebol, podendo afastar-se da casa e da vigilância de seus tutores. Nas brincadeiras intelectuais, como cientistas, por exemplo, a recorrência é maior para os meninos.

Os resultados apresentados sobre as posições ocupadas no mercado de trabalho reforçam a simbologia veiculada pelas brincadeiras consideradas adequadas para meninos e meninas. Segundo levantamento das autoras, em 43\% das obras analisadas, as meninas são representadas exercendo cuidados com a casa, enquanto os meninos aparecem apenas em 5\% dos livros analisados exercendo tal atividade. Todas as atividades que envolvem carros estão associadas aos homens e as atividades remuneradas 
associadas às mulheres são de profissões que historicamente sofreram desvalorização com a entrada da mulher no mercado de trabalho, como o magistério, por exemplo; já na área da saúde são enfermeiras, jamais médicas.

Por fim, a análise das autoras sobre os papéis de gênero aponta para a institucionalização da segregação sexual presente na representação do feminino e masculino, concluindo-se que o discurso da masculinidade hegemônica é reafirmado simbolicamente na figura do homem destemido, esportivo, provedor, bem sucedido, racional e dominador versus uma mulher dócil, que utiliza o seu tempo na realização de tarefas domésticas e maternais, submissa e sob constante vigilância de outros sujeitos sociais.

Prosseguindo nossa investigação de trabalhos acadêmicos sobre livros didáticos, encontramos o trabalho de conclusão de curso apresentado por Oliveira dos Anjos (2013), "A construção de gênero e de sexualidade no livro didático de biologia”. Segundo a autora "a linguagem e as marcas que os livros utilizam corroboram para uma construção de gênero e de sexualidade estabelecidas em padrões heteronormativos" (ANJOS, 2013, p. 06).

Anjos (2013) ordena sua pesquisa em revisão bibliográfica dos conceitos de gênero e sexualidade e análise de tais conceitos nos livros didáticos utilizados em aulas de biologia. A autora remonta discursos científicos fundamentados na diferença biológica, como o da ciência ginecológica, por exemplo, que descreve a mulher como dominada por fortes emoções resultantes das fases reprodutivas, não podendo ser responsável por suas atitudes. Tal concepção justificaria a restrição da sua atuação à esfera doméstica e a dos homens à esfera pública, sustentando o discurso da racionalidade na construção da masculinidade hegemônica.

A autora analisa três livros da coleção do (PNLD 2010), constatando um discurso heteronormativo fundamentado na diferença sexual biológica, em detrimento do conceito de construção social de gênero. Observando-se três eixos fundamentais: reprodução, contracepção e hormônios pode-se concluir que os materiais didáticos retratam apenas relações sexuais heteronormativas, centralizadas no prazer masculino e no comportamento 
sexual naturalizado pelo discurso científico do macho como ativo e em busca de numerosas cópulas em contraposição ao comportamento sexual feminino dócil, passivo, cujas funções dos órgãos genitais se limitam à reprodução e parto, com rápida menção ao clitóris.

O prazer masculino é enfatizado através do estudo da ereção e ejaculação, contudo, outras formas de estímulo são absolutamente ignoradas, assim como o prazer sexual feminino. Essa análise destaca o apagamento de outras identidades sexuais e de gênero e a homoafetividade. Enfatiza, ainda, o papel social destinado à mulher nas relações sexuais: reprodução e maternidade, cujo prazer e liberdade sexual lhe são negados. Outro ponto a ser destacado é o cuidado em apresentar causas para a impotência, sejam físicas ou emocionais, reafirmando o discurso de virilidade constituinte da masculinidade hegemônica. Cabe ressaltar ainda a falta de clareza no que se refere à responsabilidade contraceptiva, prática social fortemente associada apenas às mulheres.

O poder simbólico é a manifestação de outros poderes em situações de dominação real e pode ser claramente observado nesse estudo através da representação do feminino como a ausência: ausência da virilidade, ausência da libido, ausência do prazer, ausência do cromossomo Y, portanto, ausência de determinados hormônios, como a testosterona. Todo o texto é elaborado sob o conceito de que a ausência marca a biologia feminina, portanto, os hormônios associados à ausência do cromossomo Y proporcionam o desenvolvimento de um corpo preparado para o parto, amamentação, desenvolvido dentro do ciclo das fases reprodutivas e sujeito aos efeitos de hormônios que alteram, psico-emocionalmente, as fêmeas. Por outro lado, os homens são marcados pela presença do cromossomo Y, logo, pela presença de testosterona, hormônio associado à musculatura e força, características essenciais para o projeto de construção da masculinidade hegemônica.

Por fim, o terceiro livro do PNLD analisado por Anjos (2013) aborda gênero como uma determinação biológica assentada na diferença entre cromossomos e hormônios, apagando, 
absolutamente, o caráter social da construção de gênero e reafirmando papéis de gêneros simbolicamente violentos atribuídos aos sujeitos na sociedade. A análise dos dados apresentados por Anjos, apontam para a gravidade de certos discursos científicos, reprodutores de lógicas hegemônicas, constituídos como verdade incontestável, sob a qual repousam violência simbólica manifesta em violência de gênero.

Encerrando nosso percurso investigativo sobre estudos acadêmicos relativos aos livros didáticos, analisamos o trabalho de Tílio (2010) intitulado "Gênero e sexualidade em livros didáticos de inglês: ainda tabus?", cujo objetivo foi investigar como os livros didáticos para ensino do inglês, produzidos em países anglófonos e destinados ao mercado internacional, constroem identidades de gênero e sexualidade (TILIO, 2010, p. 01).

O autor analisou 100 obras didáticas produzidas entre 1990 e 2000, tendo sido contabilizadas oito manifestações de diversidade de gênero e sexual em apenas seis obras. $\mathrm{O}$ autor conclui que os livros ainda apresentam relações naturalizadas de gênero e sexualidade, em que o gênero é essencializado e supostamente binário, e a heterossexualidade normativa e compulsória é privilegiada. O gênero é entendido como anterior à vida social, mesmo nas obras que trazem algum questionamento sobre as diferenças entre homens e mulheres, como a coleção da New Streetwise Intermediate. Nos livros restantes, as imagens associadas à normalidade cotidiana ou às pessoas bem-sucedidas são centralizadas na figura masculina, branca, heterossexual, com atividade de alta remuneração, casada e com filhos. A mulher ocupa papel secundário, voltada para o cuidado com filhos, marido e lar, podendo possuir atividade remunerada, mas não comparável à do marido. A menção explícita à homossexualidade e bissexualidade é observada apenas em 2 livros da série Framework. No entanto, nenhuma análise crítica sobre o tema é proposta.

Conclui-se, portanto, no que se refere ao material didático de inglês, que os textos selecionados representam e reafirmam o discurso dominante de gênero, não propondo uma análise crítica sobre identidade de gênero e sexualidade, mesmo nas poucas obras em que se pode observar o tema. Tal reprodução 
do discurso hegemônico, que define e pontua todas as outras sexualidades e identidades de gênero, também é observado nas outras análises de obras didáticas apresentadas nesse artigo.

\section{CONSIDERAÇÕES FINAIS}

Toda a cultura escolar se fundamenta em textos, uma vez que toda a interação humana se dá por meio de textos - escritos ou orais - logo, uma educação inclusiva e emancipadora leva em conta a construção dos significados dos textos que circulam na esfera social, objetivando que esses significados, construídos nas práticas discursivas, possam assegurar espaço para a expressão das diversas matizes que constituem as identidades sociais.

Quando se escolhe um gênero do discurso para trabalho em sala de aula, escolhe-se também a carga ideológica veiculada por tal discurso, portanto, a construção de significados e o posicionamento dos sujeitos envolvidos na prática discursiva.

Dessa forma, trabalhar com uma diversidade de textos e suportes textuais faz parte do processo de ensino e aprendizagem. Promover o acesso a gêneros discursivos de diferentes tipos textuais - narrativos, argumentativos, descritivos, explicativos - e diferentes gêneros textuais, tais como contos, poemas, crônicas, fábulas, biografias, reportagens, verbetes, textos científicos, dentre tantos outros, permite que os estudantes - sejam crianças, jovens ou adultos - construam conhecimentos sobre os conteúdos específicos, como também sobre as características da linguagem nos diferentes textos construindo sentidos e significados.

No entanto, o que observamos nesta pesquisa, é que os livros didáticos usados na escola podem manter um discurso hegemônico de poder, no qual prevalece um discurso de "normalidade", sem que a diversidade seja tema de diálogo com os alunos e alunas.

Mesmo com o avanço dos debates sobre a diversidade de gênero e sexualidade, concluímos, nesta pesquisa, que o projeto de masculinidade dominante está ainda presente nos livros didáticos, como também nos discursos oficiais e políticas educacionais. Assim, é imprescindível voltar um olhar crítico para a elaboração de materiais e livros didáticos, analisando a carga 
ideológica veiculada pelos discursos disponíveis nas esferas sociais, dada a urgência em construir-se significados que libertem os sujeitos dos significados construídos pelas classes dominantes e, assim, assegurar a construção da igualdade e a formação cidadã de seus educandos.

\section{REFERÊNCIAS}

ANJOS, R. O. dos. A construção de gênero e de sexualidade no livro didático de biologia. $43 \mathrm{f}$. Trabalho de Conclusão de Curso (Licenciatura em Ciências Biológicas) - Instituto de Biociências, Universidade Federal do Rio Grande do Sul, Porto Alegre, Dez. 2013.

BAKHTIN, M. M.;VOLOCHÍNOV, V. N. Os gêneros do discurso. In: BAKHTIN, M. Estética da Criação Verbal. Re-edição. São Paulo: Martins Fontes, 2003, p. 277-326.

BOURDIEU, P. O poder simbólico. 7. ed. Rio de Janeiro: Bertrand Brasil S.A, 1989.

A dominação masculina. 11. ed. Rio de Janeiro: Bertrand

Brasil, 2010.

FERREIRO, E. Alfabetización: teoría y práctica. 1. ed. 1997. México: Siglo Veintiuno Editores, 1998.

FÓRUM NACIONAL DE EDUCAÇÃO (FNE). Nota do Fórum Nacional de Educação. Coordenação do Fórum Nacional de Educação. Brasília. 10 de abril de 2017. Disponível em: http://www.anped.org.br/news/nota-do-fne-sobre-bncc-10-de-abril. Acesso em: 01 jul. 2017.

FOUCAULT, M. Microfísica do poder. 8. ed. Rio de Janeiro: Graal, 1989.

A história da sexualidade.:a vontade de saber. 12. ed. Rio de Janeiro: Graal, 1997.

As palavras e as coisas: uma arqueologia das ciências

humanas. 8, ed. São Paulo: Editora Martins Fontes,1999.

FREIRE, P. Pedagogia do Oprimido. 17. ed. Rio de Janeiro: Paz e Terra, 1987. 
GROSSI, Miriam. Identidade de Gênero e Sexualidade. Antropologia em Primeira Mão, Florianópolis, n. 24, 1998 (revisado em 2012).

Masculinidades: uma revisão teórica. Florianópolis:

UFSC/ Programa de Pós Graduação em Antropologia Social, 1995.

LIMA, T. C. S. de; MIOTO, R. C. T. Procedimentos metodológicos na construção do conhecimento científico: a pesquisa bibliográfica. Rev. Katál. Florianópolis, v. 10, n. esp. p. 37-45, 2007.

MARTINS, E. de F; HOFFMANN, Z. Os papéis de gênero nos livros didáticos de ciências. Ens. Pesqui. Educ. Ciênc., Belo Horizonte, v.09, n.01, jan./june 2007.

MOITA LOPES, L. P. da. Identidades Fragmentadas: a construção discursiva de raça, gênero e sexualidade em sala de aula. 1. ed. Campinas, SP: Mercado das Letras, 2002.

SALVADOR, A. D. Métodos e técnicas de pesquisa bibliográfica. 11. ed. Porto Alegre: Sulina, 1986.

SANDENBERG, C. M. B. A violência simbólica de gênero e a lei "antibaixaria" na Bahia. Local da publicação: Editora, 2001.

TILIO, R. C. Gênero e sexualidade em livros didáticos de inglês: ainda tabus? Caderno de Letras, Rio de Janeiro, n.26, p. 48 - 61, jun. 2010.

XAVIER FILHA, C. Gênero, corpo e sexualidade nos livros para a infância. Educar em Revista, Curitiba, Edição Especial, n.01, p. 153-169, 2014.

\section{Mini-curriculum Bárbara Carvalho:}

Mestranda em Ciências da linguagem e da comunicação na Universidade de Neuchâtel (UniNe), Suíça. No Brasil, obteve os títulos de bacharel e licenciatura em Letras pela Universidade de São Paulo (USP). Possui experiência como professora alfabetizadora, de língua portuguesa e de redação nos ciclos de Educação Fundamental I e II.

E-mails para contato : barbara.angelica.carvalho@usp.br e barbara.carvalho@unine.ch 


\section{Mini-curriculum Elisabete Ferreira Esteves Campos:}

Doutora em Educação pela Universidade de São Paulo. Docente e pesquisadora do Programa de Pós-Graduação stricto sensu em Educação da Universidade Metodista de São Paulo. Coordena o Grupo de Pesquisa "Políticas de Gestão Educacional e de Formação dos Profissionais da Educação”.

E-mail paracontato: elisabete.campos@metodista.br 